$9-1-2018$

\title{
Making the business case for social and behavior change programming
}

Breakthrough RESEARCH

Follow this and additional works at: https://knowledgecommons.popcouncil.org/departments_sbsr-rh How does access to this work benefit you? Let us know!

\section{Recommended Citation}

Breakthrough RESEARCH. 2018. "Making the business case for social and behavior change programming," Activity brief. Washington, DC: Population Council. 


\section{Making the Business Case for Social and Behavior Change Programming}

Breakthrough RESEARCH will gather, analyze, and present evidence on the impact and costs of social and behavior change (SBC) interventions with the aim of making the case that SBC programming is crucial for improving health and advancing development.

\section{WHY ARE WE DOING THIS ACTIVITY?}

Decision-makers need evidence regarding the benefits and costs of health interventions before deciding whether and how much to invest in them. Breakthrough RESEARCH's literature review to date has shown that the lack of such information on SBC has created an incomplete picture of its contribution to health outcomes. Further, the quality and rigor of many studies have been insufficient to confidently make the case for investing in SBC.

Several types of analyses can address this information gap, including costing, cost-effectiveness analysis, and cost-benefit analysis:

- A costing exercise calculates the monetary value of all resources required to carry out an intervention-e.g., labor, commodities, supplies, equipment, vehicles and other transport, supervision, management, space, and utilities. Unit costs can then be expressed as total costs per-person, per-event, or per-service.

- Cost-effectiveness analysis evaluates interventions in terms of how much they cost to achieve certain health outcomes. For example, a study may find that it costs $\$ 50$ for an SBC intervention to avert one unintended pregnancy (through family planning use).

- Cost-benefit analysis expresses program benefits in monetary terms, e.g., the cost savings to the health system resulting from an additional family planning user. Researchers may also use standard conversion factors to translate an outcome such as reduction of unintended

\section{ACTIVITY SNAPSHOT}

Gather and present evidence on the costs and benefits of SBC approaches

LEAD PARTNER

GEOGRAPHIC LOCATION

Avenir Health

Global

ANTICIPATED TIMELINE

2018 - 2019

CONTACT

Jim Rosen at

jrosen@avenirhealth.org

pregnancy into disability-adjusted life years (DALYs) saved. The cost per DALY of a country program can then be compared with international standards.

\section{HOW WILL THIS ACTIVITY BE IMPLEMENTED?}

Breakthrough RESEARCH is pursuing a three-pronged strategy to build evidence that will help assess the value of SBC programming.

1. Review and synthesize existing literature on program effectiveness, costs, cost-effectiveness, and cost-benefit analysis. The research team will identify and compile published studies on unit costs, cost-effectiveness, and cost-benefit results for SBC related to family planning and synthesize key elements of their methodology and findings. To make this information more widely available, the project will produce a summary of the literature, a 
searchable repository of SBC impact and costing studies in an Excel spreadsheet, and case examples to illustrate the findings of these studies.

2. Develop and pilot costing guidelines for donors, implementing organizations, and researchers. In consultation with its sister project, Breakthrough ACTION, and SBC implementing partners, Breakthrough RESEARCH will develop costing guidelines for researchers, program managers, and others for collecting and documenting the costs of SBC interventions. The guidelines will include sections on measuring the use of resources, pricing and valuation, and presentation of results. To complement other existing guidelines on health costing, Breakthrough RESEARCH's guidelines will emphasize what is different or unique about costing SBC interventions. The guidelines will be piloted in countries where the Breakthrough consortium has ongoing activities.

3. Develop modeling approaches to estimate SBC cost-effectiveness and cost-benefit ratios with existing, country-level data. Breakthrough RESEARCH plans to use modeling approaches to estimate country-level cost-effectiveness and cost-benefit ratios for SBC activities. The SBC modeling approach builds on previous work done by Avenir Health, including for HIV (the Goals model), family planning (FP Goals model), maternal and child health, and other health areas. These models enable researchers and policy analysts to answer such questions as: How much funding is required to achieve the health goals of a country's strategic plan? What health goals can be achieved with available resources? Or, how would alternate patterns of resource allocation affect the achievement of program goals? The models' results also provide additional evidence for program advocacy.

\section{HOW WILL THE OUTCOMES HELP IMPROVE SBC PROGRAMS?}

Breakthrough RESEARCH will first develop a business case for investing in SBC in family planning and later expand to SBC approaches in other health sectors. The initial business case will aim to:

\section{ANTICIPATED PRODUCTS}

- Literature review summary

- Searchable SBC costing repository in Excel

- Case studies showing value of SBC

- Guidelines for cost-effectiveness analysis and cost-benefit analysis

- Model to simulate SBC program costs and effects

- Business case report/presentation for SBC in family planning

- Business case for SBC in other health programs

- Bolster support for family planning SBC efforts by providing evidence that such efforts are key to achieving family planning, and hence public health, goals.

- Synthesize the available evidence on SBC impact and cost-effectiveness to support the case for maintaining or increasing the funding for family planning SBC efforts.

- Provide evidence and decision-making tools for investing in SBC approaches with the greatest potential for impact and cost-effectiveness.

More broadly, this activity will generate evidence on SBC program costs, outcomes, and impact. It aims to show whether SBC interventions are cost-effective and whether they produce significant monetary benefits in relation to their cost, which is useful for donor agencies and health officials who make funding decisions. The activity complements Breakthrough ACTION's global influence strategy to increase funders' and program planners' commitment to SBC programming.

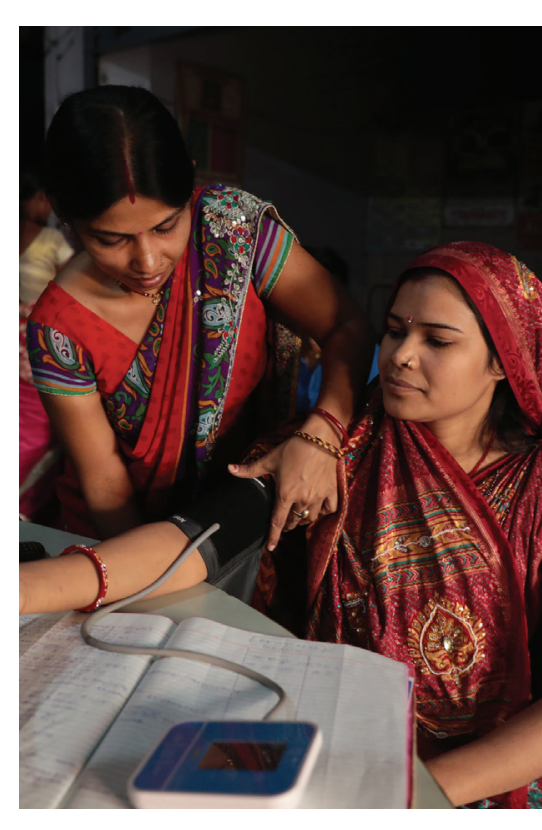

\section{Breakthrough RESEARCH}

This activity is being implemented as part of Breakthrough RESEARCH. Breakthrough RESEARCH catalyzes social and behavior change (SBC) by conducting state-of-the-art research and evaluation and promoting evidence-based solutions to improve health and development programs around the world. Breakthrough RESEARCH is a consortium led by the Population Council in partnership with Avenir Health, ideas42, Institute for Reproductive Health at Georgetown University, Population Reference Bureau, and Tulane University.

\section{Acknowledgements}

Breakthrough RESEARCH is made possible by the generous support of the American people through the United States Agency for International Development (USAID) under the terms of cooperative agreement no. AIDOAA-A-17-00018. The contents of this document are the sole responsibility of the Breakthrough RESEARCH and Population Council and do not necessarily reflect the views of USAID or the United States Government.

\section{Breakthrough RESEARCH}

Population Council

4301 Connecticut Avenue, NW

Suite 280

Washington, DC 20008

Tel: +1 2022379400

breakthroughactionandresearch.org

\section{Photo Credits}

Paula Bronstein /The Verbatim Agency/Getty Images 